\title{
Correction to: The Role of Ethnicity in Child and Youth Care Practice: "When They Heard My Last Name, They Suddenly Respected Me"
}

\author{
Liat Yakhnich $^{1,2}$ (D) Keren Michael ${ }^{3}$ (D) $\cdot$ Galit Yanay-Ventura ${ }^{3}$ (D)
}

Published online: 5 February 2021

(c) Springer Science+Business Media, LLC, part of Springer Nature 2021

\section{Correction to: Child \& Youth Care Forum https://doi.org/10.1007/s10566-021-09603-7}

Unfortunately, in the original version of this published paper, some of the blinded contents to our own publications were omitted. The original version is updated.

1. Under section "CYC in Israel” in para starting "The Israeli CYC practitioners' target population is ..." line number 6 should read as "Michael \& Ben-Zur, 2007". The complete sentence is "These difficulties may be related to multiple personal, familial, and social factors (Fosco et al. 2019; Kwan et al. 2015; Michael and Ben-Zur 2007).

2. In the same paragraph, line number 11 should read as "Yakhnich et al., 2019". The complete sentence is "In Israel, as in other countries, marginalization is strongly linked to ethnic origin (Alon, 2015; Cohen, Haberfeld, \& Kristal, 2013), with ethnic minority and immigrant youth often facing the cumulative repercussions of deprivation, discrimination, and restricted access to social and educational resources (Lavie-Ajayi and Krumer-Nevo, 2013; Walsh et al. 2015; Watt and Kim 2019; Yakhnich et al. 2019)".

3. Under section "Instruments and Procedure" in para starting "The interviewers contacted potential candidates ..." line number 7 should read as "Yanay-Ventura et al., 2020". The complete sentence is "The sampling continued until theoretical saturation was achieved, signified by the point at which new issues no longer emerged from the

The original article can be found online at https://doi.org/10.1007/s10566-021-09603-7.

Liat Yakhnich

liatyakhnich@gmail.com

Keren Michael

kerenmi@yvc.ac.il

Galit Yanay-Ventura

gality@yvc.ac.il

1 Department of Youth Development, Beit Berl College, 4490500 Beit Berl, Israel

2 Avshalom str. 6c, 38245 Hadera, Israel

3 Department of Human Services, The Max Stern Yezreel Valley College, 19300 Yezreel Valley, Israel 
interviews (Creswell and Clark 2007; Yanay-Ventura et al. 2020), and lasted three months".

4. Under section "Data Analysis and Trustworthiness" in para starting "Data analysis was performed by the researchers ..." line number 2 should read as "Yanay-Ventura et al. 2020". The complete sentence is "Data analysis was performed by the researchers who coded the interviews and conducted a joint discussion of the extracted themes (YanayVentura et al. 2020)".

\section{References}

Michael, K., \& Ben-Zur, H. (2007). Risk-taking among adolescents: Associations with social and affective factors. Journal of Adolescence, 30, 17-31. https://doi.org/10.1016/j.adolescence.2005.03.009.

Yanay-Ventura, G., Issaq, L., \& Sharabu, M. (2020). Civic service and social class: The case of young Arab women in Israel. VOLUNTAS: International Journal of Voluntary and Nonprofit Organizations. https ://doi.org/10.1007/s11266-020-00210-z.

Yakhnich, L., Pounko, I., \& Walsh, S. D. (2019). The hidden matrix: Perspectives of youth and their parents on immigration and youth delinquent behavior. Journal of Cross-Cultural Psychology, 50(4), 615-636. https://doi.org/10.1177/0022022119832128.

Publisher's Note Springer Nature remains neutral with regard to jurisdictional claims in published maps and institutional affiliations. 